\title{
Extreme Atmospheric Radiation Environments \& Single Event Effects
}

\author{
Clive Dyer, Senior Member, IEEE, Alex Hands, Member, IEEE, Keith Ryden, Member IEEE, \\ Fan Lei, Member IEEE
}

\begin{abstract}
Data from ground-level radiation monitors and cosmogenic nuclides are combined to a give a probability distribution for severe radiation events related to the well quantified event of 23 February 1956. Particle fluxes, single event effects rates and dose rates are calculated for groundlevel and aerospace systems. The event of February 1956 would provide a challenge to air safety while more extreme events seen in historical records would challenge safety-critical ground systems. A new space weather hazard scale based on this event could be used to give rapid assessment of the radiation hazard using high latitude neutron monitor data.
\end{abstract}

\section{INTRODUCTION}

$\mathrm{IN}$ recent years there has been a growing awareness of the threat posed to electronics by single event effects (SEEs) caused by the atmospheric radiation environment produced by galactic cosmic radiation; e.g. [1-3]. However to date there have been few attempts to quantify the influence of increases due to solar particles, commonly known as ground level enhancements (GLEs). Standards exist for soft errors at sea level [4] and for all single event effects at aircraft altitudes [5]. The former does not currently consider solar particles, whilst the latter makes mention of certain recent events, such as 23 February 1956 and 29 September 1989, as assessed in work such as [6]. There is a need to provide sensible hardening levels for atmospheric systems and recently an advisory annex on Space Weather has been added to the International Electrotechnical Commission (IEC) standard [7]. The work described here is aimed at supporting this as well as other ongoing studies on aviation and space weather, such as the NASA-funded Safety during Aviation Flight Events from SEP and cosmic ray bacKground high-energY particles(SAFESKY) Institute. [8]. In addition this work can provide specifications for safety-critical, ground-level systems, such as nuclear power where event probabilities of 1 in 10000 years have to be considered. These energetic particle events are also important for manned spaceflight since these particles are able to penetrate the geomagnetic and physical shielding afforded to astronauts.

C. Dyer is with Surrey Space Centre and CSDRadConsultancy, Fleet, UK, (Corresponding author telephone: +44 1252629972; e-mail: clive.dyer@btinternet.com). A. Hands, K. Ryden are with Surrey Space Centre, University of Surrey, Guildford, UK GU2 7JP. F. Lei is with RadMod Research, Camberley, UK.
Space Weather has come to the attention of governments in recent years and has been the subject of a number of reports, for example the report of the UK Royal Academy of Engineering [9], which posed the question as to what would be the influence on critical infrastructure of a repeat of the first ever flare to be observed in white light by Carrington and Hodgson on 1 September 1859. Single event effects (SEE) in systems from sea level to space were identified as being of great importance and requiring further study. This event had enormous geomagnetic consequences as evidenced by magnetometers, low latitude aurorae and the response of the technology of the era, such as large currents in telegraph lines. There were no measurements possible for other influences such as ionising radiation and so we must infer their possible magnitudes using proxies and size distributions of more recently observed smaller events.

\section{GROUND LEVEL ENHANCEMENTS}

These are a small but potent subset of solar particle events which have hard spectra with a significant component at particle energies greater than $300 \mathrm{MeV}$ giving sufficient fluxes of secondary particles (neutrons, muons etc.) to reach sea level. Ground-level ionisation chambers were first deployed in 1932 and a network was established by Scott Forbush in 1936 [10]. Major increases were first detected in February and March of 1942 followed by July of 1946 [11]. Forbush tentatively suggested a solar origin and despite much initial resistance these events were eventually accepted as coming from the Sun.

These monitors were sensitive to directly ionising secondaries such as muons. In 1948 Simpson [12] invented the neutron monitor to give vastly improved sensitivity to both cosmic rays and solar particles. These were increasingly deployed across the globe in anticipation of the International Geophysical Year which ran from July 1957 to December 1958. In 1956 there were some 17 monitors active when the largest event of modern times occurred on 23 February 1956 [13] (this event will subsequently be abbreviated as Feb56). The maximum increase recorded by a neutron monitor was at Leeds UK where neutron fluxes some 50-times background were reached within 15 minutes (this was the time resolution of the monitor at the time). The increase was so dramatic that some observers switchedoff their monitors believing them to be malfunctioning. However sufficient measurements were taken to well characterise the event. Up until July 2017, some 71 GLEs had been measured as illustrated in Figure 1, which shows 


\section{Paper presented at IEEE Nuclear and Space Radiation Effects Conference, New Orleans, 17-21 July 2017 Accepted for publication in IEEE Transactions on Nuclear Science, January 2018}

the maximum increases as points together with a smoothed plot of the sunspot number, which is a commonly accepted measure of solar activity. The ionisation chamber data have been normalised to high latitude neutron monitor data [14], while the latter are obtained from [15]. Sea-level monitors have been used but the partial geographic coverage afforded by the available monitors at any given time means that there could have been larger increases at other locations.

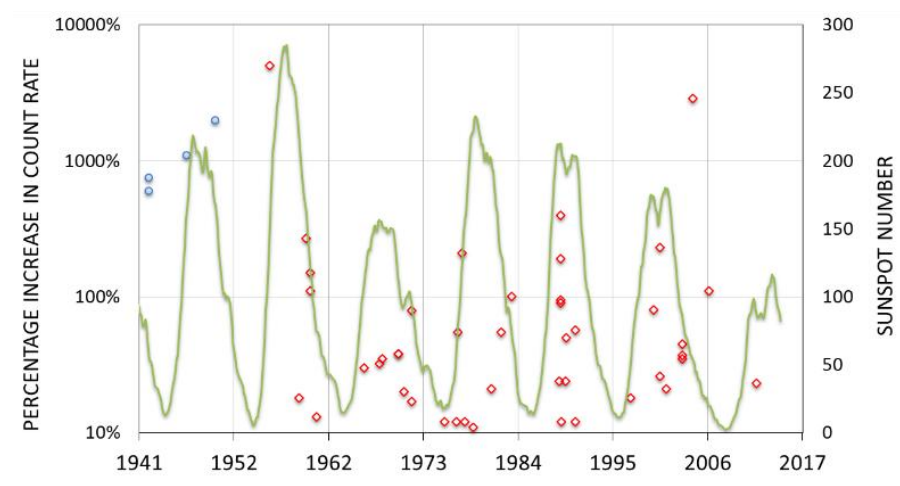

Figure 1: Peak intensities of GLEs cf. sunspot number. Blue points are from ionisation chambers and red points are from neutron monitors. The plot has a threshold of $10 \%$ and notably large events greater than $1000 \%$ occurred in July 1946, November 1949, February 1956 and January 2005. For the latter the maximum intensity plotted occurred in the Antarctic region and northern hemisphere levels were some factor ten less.

Current neutron monitor networks include the Neutron Monitor Data-Base (NMDB) [16], established under ESA sponsorship, and the Spaceship Earth network [17] operated by the Bartol Research Institute of the University of Delaware. These networks provide alert systems triggered when several monitors show increases above certain thresholds.

The time profile of the Feb56 event as measured at four widely-dispersed stations is shown in Figure 2. The greatest increase was seen at Leeds despite its geomagnetic latitude being well below that of Ottawa so that it should be better shielded magnetically. The ability of a particle to penetrate the geomagnetic field is measured by its momentum-tocharge ratio or rigidity in GV. The cut-off rigidity at a given location is the minimum rigidity required to penetrate the magnetic field (usually taken as arriving from the vertical direction) and was about $2 \mathrm{GV}$ for Leeds and $1 \mathrm{GV}$ for Ottawa in 1956. The larger increase at Leeds is due to the large anisotropies that occur in the early phases of many GLEs due to propagation along the interplanetary magnetic field lines from Sun to Earth. The rise-time is less than the 15-minute time resolution of the Leeds instrument and the particle onset at $0345 \mathrm{UT}$ is almost contemporaneous with the observed solar flare at 0334 to 0340 UT. Recently higher time-resolution data from ionisation chambers have been re-examined [18] and show the particle intensity risetime to be only 48 seconds. The time-profile is of great significance both in terms of warnings and avoidance and in terms of defining the hazard, as clearly the rate of occurrence of SEEs is important for error correction techniques and system design. The major event of 20 January 2005 was also extremely anisotropic and had a very sharp rise-time. We are fortunate that the maximum of the event hit unpopulated regions in Antarctica where air flights are extremely uncommon.

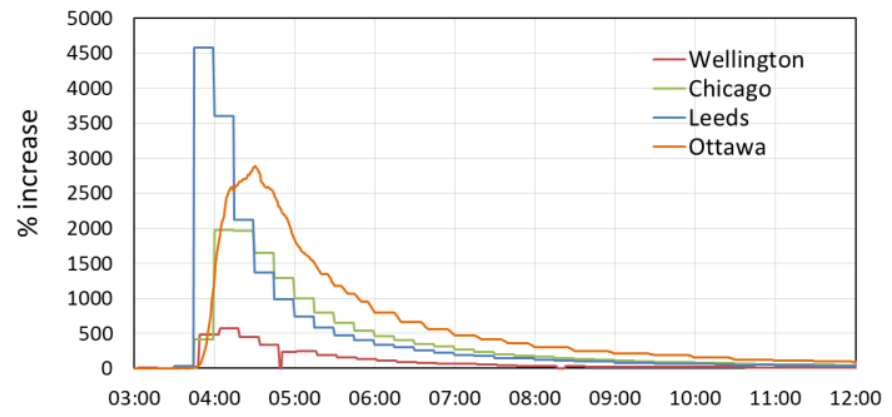

Figure 2: Profiles of the event of 23 February 1956 are compared. The Leeds station showed the maximum increase of $4581 \%$ followed by Ottawa (2802\%), Chicago (1976\%) and Wellington (575\%).

\section{HISTORIC EVENTS}

Prior to 1942 we have only indirect measurements of cosmic radiation and solar particle events from cosmogenic nuclides such as $\mathrm{Be} 10$ and $\mathrm{Cl} 36$ in ice cores, $\mathrm{C} 14$ in tree rings and possibly from nitrates in ice cores [19], [20]. The nitrate analysis is now in dispute [21].]. Results on Be10, $\mathrm{Cl} 36$ and $\mathrm{C} 14$ appear to be better founded, showing events some $30 \mathrm{x}$ the February 1956 event in AD774 and 15x Feb56 in AD994 [22]. These nuclides were detected at enhanced levels in geographically widely dispersed ice core drillings (several sites in Greenland and Antarctica) and tree ring samples (German Oaks and Japanese Cedars) and the relative amounts of $\mathrm{Cl} 36$ and $\mathrm{Be} 10$ imply that these large events had hard spectra similar to GLEs in Feb56 and January 2005. Also, although the 1859 event does not show a significant feature, there appear to be some 7 events per century comparable to Feb56 ( 0.5 to $1.0 \mathrm{x}$ ) between 1800 and 1983 [23]. The absence of any signal from 1859 is probably due to the location of the flare event at $10^{\circ} \mathrm{W}$ on the Sun. This is a favourable location for major geomagnetic storms from coronal mass ejections but not for major particle events that originate further westward (e.g. $80^{\circ} \mathrm{W}$ for February 1956).

In Figure 3 we combine the modern data from [14] and [15] with cosmogenic nuclide data from [22] to give a probability distribution for event sizes. We use the peak fluxes and compare with the Feb56 event. Clearly this is a tentative procedure, particularly for the cosmogenic events which could comprise more than one event given the approximately 2-year resolution of the data. Given this and the poor statistics it is difficult to come to firm conclusions on events of Feb56 size and beyond but there is tentative evidence of a turnover for very large events. This is consistent with Usoskin \& Kovoltsov [24] who find no evidence for events beyond 50-100 x Feb56. For events of 0.4 to 1.0x Feb56 there have been very few direct measurements as reflected in the large error bars. However adding the data from McCracken and Beer [23] would raise these points to the top of the error bars and suggest that recent history has been kind to us. Interestingly, interpolating between the direct measurements and cosmogenic data suggests that the occurrence rate of a $4 \mathrm{xFeb} 56$ event is around 1 per 150 years, so that although 
Paper presented at IEEE Nuclear and Space Radiation Effects Conference, New Orleans, 17-21 July 2017 Accepted for publication in IEEE Transactions on Nuclear Science, January 2018

the Carrington-Hodgson event itself was not this intense the use of $4 \mathrm{xFeb} 56$ for 1 in 150 year events appears reasonable.

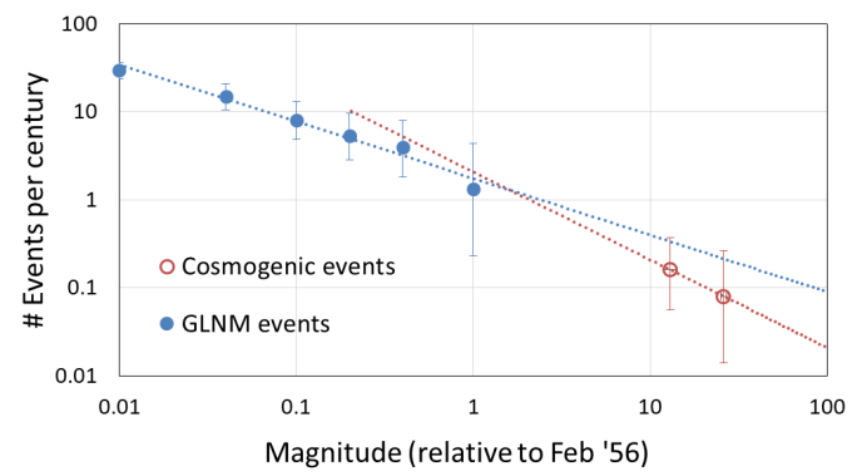

Figure 3: The occurrence probability (in events per century) of events exceeding a certain peak flux is plotted as a function of this flux measured with respect to the event of 23 February 1956.

Events comparable to and greater than Feb56 are quite probable and so safety-critical systems must survive or avoid them (e.g. by shut-down of ground systems or grounding of flights). Hence we will characterise Feb56 as a yardstick for quantifying hazards

\section{THE 23 FEBRUARY 1956 ENVIRONMENT AND EFFECTS}

Recent work by Tylka and Dietrich [25] has examined the proton spectra of major GLEs using asymptotic cones of acceptance and response functions for ground-level neutron monitors (GLMNs). These have been obtained for the isotropic phase of the events and do not account for the initial pulse such as observed by the Leeds monitor. The inferred spectra are plotted in Figure 4 with alternative fits obtained from exponential functions and by a gradually breaking power law (Band fit). The latter is used here.

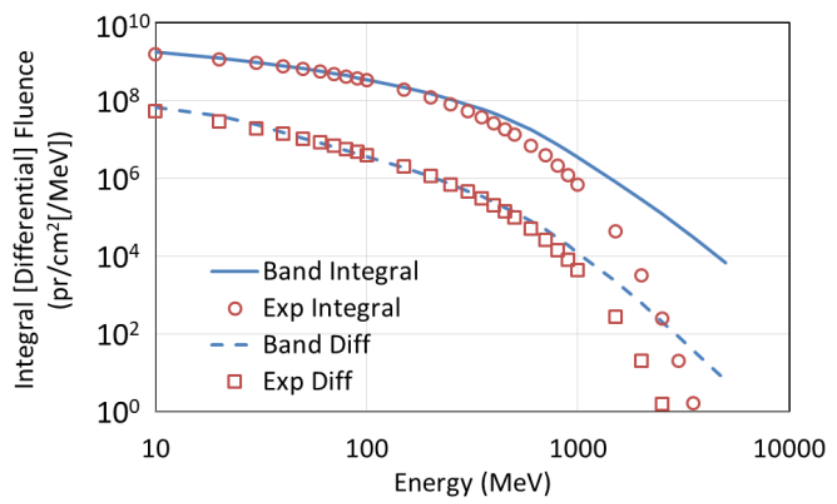

Figure 4. Proton spectra for the event of 23 February 1956 as derived in [25]. Note that the points are obtained by the fitting procedure and are not data points.

In order to get a worst-case environment we calibrate the observations of the Leeds monitor with the ground-level cosmic ray neutron fluxes calculated for that location using the Models for Atmospheric Ionising Radiation Effects (MAIRE) [26]. MAIRE is based on a matrix of atmospheric secondary particle fluxes generated using the FLUKA Monte Carlo code for a range of incident proton and ion energies covering the range of solar particles and galactic cosmic rays (GCRs). Cut-off rigidities and their variations with magnetic field and geomagnetic disturbances are generated using trajectory integrations. A selection of GCR spectra and the solar proton spectra from [25] may then be used to generate secondary particle fluxes and dose to humans (ambient dose equivalent or effective dose). The particle fluxes may be combined with measured SEE crosssections to calculate SEE rates. Computations of these can be made for point locations or along input aircraft routes. A fuller description of the MAIRE codes and validations with balloon data are given in reference [27].

In order to calculate an adjustment factor for the anisotropy of the Feb56 event, we compare the predicted percentage increase of a ground level neutron monitor (using MAIRE fluxes for GCR and Feb56) with the measured value. As the ground-level neutron spectrum during a GLE differs from that during quiescent GCR conditions, we multiply ground level neutron fluxes with a neutron monitor response curve.

Figure 5 shows a response function for the IGY-type neutron monitor (which was the type used at Leeds in 1956), as derived by Clem and Dorman [28]. The response function of the alternative NM-64 design is also shown for comparison. Ground-level neutron fluxes are shown in Figure 6, demonstrating that the enhancement in the neutron spectrum during Feb56 occurs up to a neutron energy of a few hundred MeV. This is reflected in the relative contributions of different neutron energies to the GLNM count rate. We use the IGY response curve and the ground level fluxes to calculate the contribution to total GLNM count rate as a function of neutron energy for each environment. This is shown as a counts per unit lethargy plot in Figure 7.

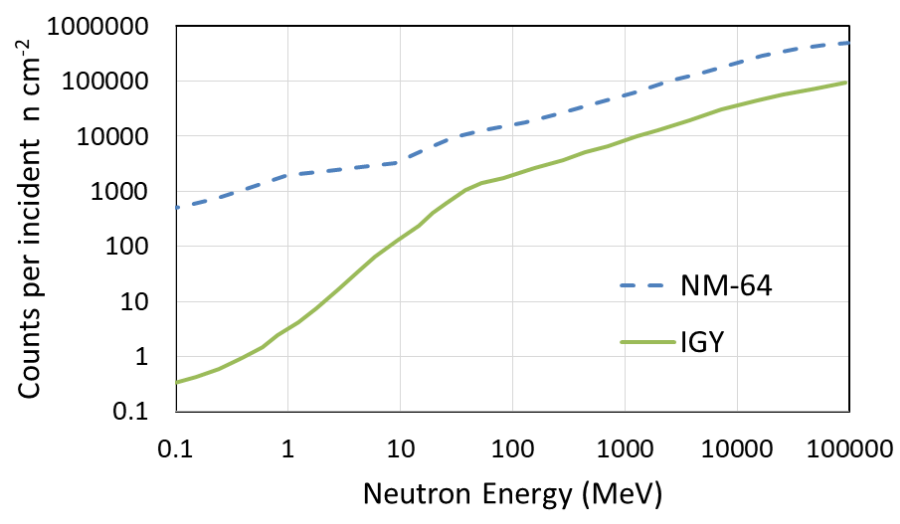

Figure 5. Response functions for two types of ground level neutron monitor. Count rates are given per unit fluence based on normal incidence. Given the approximately isotropic nature of the ground level neutron flux, absolute count rates are overestimated but relative count rates are stable. 
Paper presented at IEEE Nuclear and Space Radiation Effects Conference, New Orleans, 17-21 July 2017 Accepted for publication in IEEE Transactions on Nuclear Science, January 2018

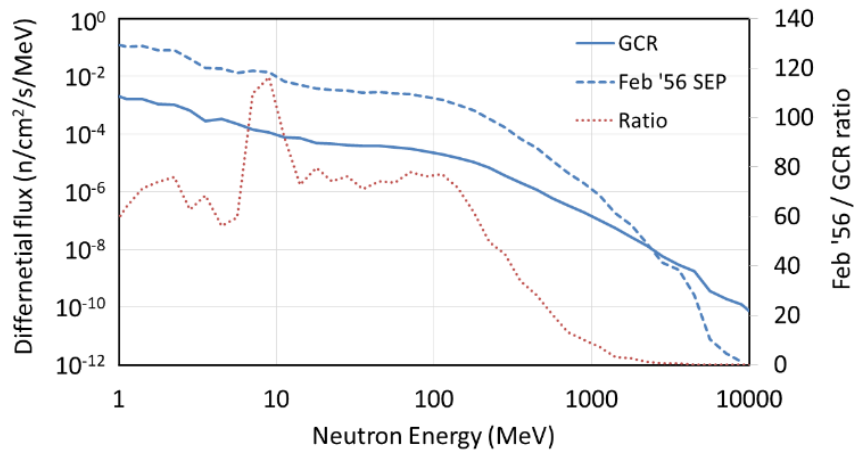

Figure 6. Ground-level neutron fluxes during GCR conditions and the Feb56 event. The ratio between the two is shown on the right hand axis.

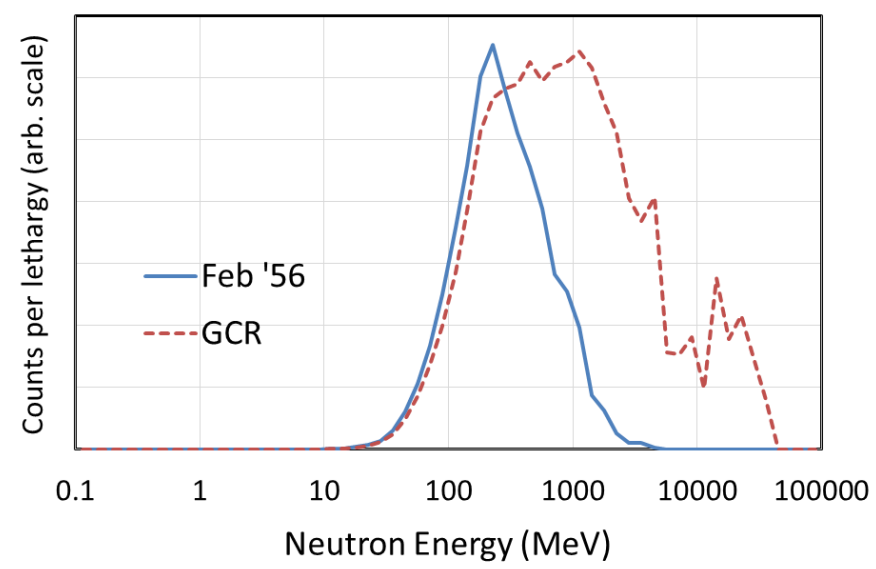

Figure 7. Relative contributions to ground-level neutron monitor count rate during GCR conditions and during the Feb56 event. The y-axis is a linear counts per lethargy scale, such that equal areas under the curve represent equal contributions to the overall count rate.

It is clear that the GLNM count rate in GCR conditions is due to neutrons spanning a wide energy range, but dominated by those with $100 \mathrm{MeV}-10 \mathrm{GeV}$. By contrast, due to the lower average primary proton energy, the GLNM count rate during a Feb56 event is dominated by neutrons of a few hundred $\mathrm{MeV}$.

The predicted increase in count rate at the Leeds IGY neutron monitor during the Feb56 event is $2372 \%$, based on the Tylka and Dietrich global average spectrum. This compares to the measured increase, over a 15 minute averaging period, of $4581 \%$. Hence, in order to account for the anisotropy factor that caused a disproportionate enhancement in the intensity of Feb56 at Leeds, we need to upscale MAIRE-derived fluxes by a factor of 1.9. This is not necessarily the worst case, other geographic locations may have been even more favoured by the anisotropy.

The correction factor for the anisotropic initial phase compared with the calculations of [25] and [26] is found to be $1.9 \mathrm{We}$ then use this in conjunction with MAIRE to calculate secondary particle fluxes as a function of altitude and for 2 example locations with cut-off rigidities of 2.5 and $0.0 \mathrm{GV}$. The fluence rates per hour of neutrons and protons for ground level and 40000 feet are given in Table 1 for two latitudes/cut-off rigidities. The energy threshold of $10 \mathrm{MeV}$ for neutrons is commonly used in the literature and in standards as single event effects commonly have cross-sections that plateau above this energy and fall-off rapidly below. Fuller discussions of the influence of lower energy neutrons can be found in the IEC standard [5] and in references such as [29-30]. Similar considerations apply to the nuclear interactions of protons but they must penetrate some intervening material in which they lose energy by ionisation. Hence a somewhat higher energy of $20 \mathrm{MeV}$ is chosen. The scope of this paper is to illustrate the scale of the problem and give approximate SEE rates. More accurate calculations require the spectra to be transported through shielding materials and device structures.

For technologies of below $65 \mathrm{~nm}$ feature size, direct ionisation by stopping protons, electrons, and muons becomes important, together with negative muons being captured onto nuclei, e.g. [31-32]. The fluence rates for electrons and muons are given in Table 2. Again the thresholds used are chosen to illustrate the problem and compare environments. Accurate estimates of SEE rates require further work on radiation transport through shields and devices, e.g. [33]. To date such work has concentrated on secondaries from galactic cosmic rays and it is recommended that in future solar particle events are included in assessments. Pions are also present and can give nuclear interactions but fluences are at least 4 orders of magnitude lower than for neutrons for the Feb56 spectrum both at sea level and at 40000 feet. Given the sharp time profile of the Feb56 event the instantaneous rates in the first few minutes will be much higher than these numbers and more challenging. These calculations can then be used in conjunction with Figure 3 to give fluxes and frequencies of occurrence for other events.

TABLE 1

CAlculated Peak Fluence Rates aVeraged over 1 hour for EVENT OF 23 FEBRUARY 1956

NEUTRONS AND PROTONS

\begin{tabular}{|l|c|c|c|c|}
\hline Altitude kft & $\begin{array}{c}\text { Neutrons } \\
\mathrm{cm}^{-2} \mathrm{hr}^{-1} \\
>10 \mathrm{MeV} \text { at } \\
51.5 \mathrm{~N}, 0 \mathrm{~W} \\
2.5 \mathrm{GV}\end{array}$ & $\begin{array}{c}\text { Protons } \\
\mathrm{cm}^{-2} \mathrm{hr}^{-1} \\
>20 \mathrm{MeV} \\
\text { at } 51.5 \mathrm{~N}, \\
0 \mathrm{~W}, 2.5 \mathrm{GV}\end{array}$ & $\begin{array}{c}\text { Neutrons } \\
\mathrm{cm}^{-2} \mathrm{hr}^{-1} \\
>10 \mathrm{MeV} \text { at } \\
80.0 \mathrm{~N}, 0 \mathrm{~W} \\
0.0 \mathrm{GV}\end{array}$ & $\begin{array}{c}\text { Protons } \\
\mathrm{cm}^{-2} \mathrm{hr}^{-1} \\
>20 \mathrm{MeV} \\
\text { at } 80.0 \mathrm{~N}, \\
0 \mathrm{~W}, 0.0 \mathrm{GV}\end{array}$ \\
\hline 0 & $5.2 \times 10^{2}$ & $2.1 \times 10^{1}$ & $2.8 \times 10^{3}$ & $5.5 \times 10^{1}$ \\
\hline 20 & $4.4 \times 10^{4}$ & $3.9 \times 10^{3}$ & $3.9 \times 10^{5}$ & $1.3 \times 10^{4}$ \\
\hline 40 & $2.9 \times 10^{5}$ & $6.7 \times 10^{4}$ & $5.8 \times 10^{6}$ & $5.1 \times 10^{5}$ \\
\hline 60 & $4.7 \times 10^{5}$ & $2.2 \times 10^{5}$ & $2.1 \times 10^{7}$ & $7.5 \times 10^{6}$ \\
\hline
\end{tabular}

TABLE 2

Calculated Peak Fluence Rates AVeraged over 1 HOUR For EVEnT OF 23 FEBRUARY 1956

ELECTRONS AND MUONS

\begin{tabular}{|c|c|c|c|c|}
\hline Altitude kft & 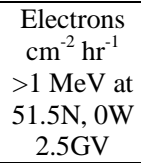 & $\begin{array}{c}\text { Muons } \\
\mathrm{cm}^{-2} \mathrm{hr}^{-1} \\
>1 \mathrm{MeV} \text { at } \\
51.5 \mathrm{~N}, 0 \mathrm{~W}, \\
2.5 \mathrm{GV}\end{array}$ & 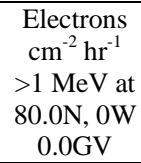 & $\begin{array}{c}\text { Muons } \\
\mathrm{cm}^{-2} \mathrm{hr}^{-1} \\
>1 \mathrm{MeV} \text { at } \\
80.0 \mathrm{~N}, 0 \mathrm{~W}, \\
0.0 \mathrm{GV}\end{array}$ \\
\hline 0 & 20 & 20 & 39 & 21 \\
\hline 20 & $3.1 \times 10^{3}$ & $1.0 \times 10^{3}$ & $9.0 \times 10^{3}$ & $1.3 \times 10^{3}$ \\
\hline 40 & $4.7 \times 10^{4}$ & $1.1 \times 10^{4}$ & $2.0 \times 10^{5}$ & $2.2 \times 10^{4}$ \\
\hline 60 & $1.2 \times 10^{5}$ & $2.2 \times 10^{4}$ & $8.5 \times 10^{5}$ & $8.6 \times 10^{4}$ \\
\hline
\end{tabular}

These fluxes can be translated into SEE rates if crosssections are known and into ambient dose equivalent rates 

Paper presented at IEEE Nuclear and Space Radiation Effects Conference, New Orleans, 17-21 July 2017
Accepted for publication in IEEE Transactions on Nuclear Science, January 2018

for personnel using coefficients in MAIRE. In Table 3 example single event upset (SEU) rates at $40 \mathrm{kft}$ and $0 \mathrm{GV}$ cut-off rigidity are given for 1 Gbyte of an SRAM, taken as having a plateau cross-section $>10 \mathrm{MeV}$ of $5 \times 10^{-14} \mathrm{~cm}^{2}$ per bit, to compare with the previous estimates of [6]. This uses the neutron and proton fluxes from Table 1 as this generation of SRAM was sensitive only to nuclear interactions and ionisation by heavy ions. Increased rates cf. [6] (by a factor 4.3) are due to the improved calculation techniques of [25] and allowance for the initial anisotropy. It should be noted that devices have been tested that are some tenfold worse than these figures and that sensitivity of devices of that generation to thermal neutrons can also give this order of increase. An example of a sensitive SRAM included in avionics equipment was reported in [34] and this upset on-average every 200 flight hours under background cosmic rays. This single chip would upset every 5 minutes in a Feb56 event. Also given are single event latchup (SEL) rates for a SRAM showing latchup (the so-called Hitachi-B chip reported in [35], which had a cross-section of $1.5 \times 10^{-9} \mathrm{~cm}^{2}$ per 4-Mbit device averaged over a spallation neutron source spectrum representative of the atmospheric spectrum. This was apparently deployed in certain avionics and experienced latchups from background cosmic rays. If these were widely deployed across many aircraft, there would be multiple failures during the first hour of a Feb56 event, particularly in flights at high latitude and altitude, such as transatlantic flights between USA and Europe. It should be noted that SEL cross-sections often have a cross-section that increases with energy (e.g. [3536]) and that accurate estimation of SEL rates requires consideration of the differences in spectra between sea level and flight altitude and between cosmic ray, solar particle and ground accelerator test facilities. A further important example is given for $\mathrm{n}$-channel power MOSFETs taking data from [37]. Testing of 8 different devices in spallation neutron sources showed single event burn-out (SEB) in 6 devices with cross-sections at full rated voltage from $3 \times 10^{-7}$ to $1.2 \times 10^{-6} \mathrm{~cm}^{2}$. All of these devices would definitely fail for these flight conditions during a Feb56 event while $0.35 \%$ would fail on the ground at high latitudes. This illustrates the necessity of device characterisation and selection together with adequate de-rating for all safetycritical applications from ground to space.

TABLE 3

EXAMPLE SEE RATES AND AMBIENT DOSE EQUIVALENT RATES AT 40000 FEET AND 0 GV FOR EVENT OF 23 FEBRUARY 1956

\begin{tabular}{|c|c|}
\hline SEU RATE PER HOUR PER GBYTE & 2520 \\
\hline $\begin{array}{c}\text { SEL RATE PER HOUR PER CHIP } \\
\text { (4MBIT) }\end{array}$ & 0.01 \\
\hline $\begin{array}{c}\text { SEB RATE PER HOUR FOR N- } \\
\text { CHANNEL POWER MOSFETS }\end{array}$ & 1.8 TO 7.5 \\
\hline $\begin{array}{c}\text { AMBIENT DOSE EQUIVALENT RATE } \\
\text { PER HOUR (MILLISIEVERTS) }\end{array}$ & 5.8 \\
\hline
\end{tabular}

Also calculated is the ambient dose equivalent rate which may be compared with recommended annual limits for aircrew in Europe of $6 \mathrm{mSv}$ per year.

\section{Time Profile of Events}

The recent work of McCracken, Shea and Smart [18] using ionisation chamber data shows the Feb56 event to be highly impulsive and instantaneous rates within the first 15 minutes to be very high. Because these high rates can challenge protection and avoidance procedures it is necessary to define a worst-case time profile. Using the ionisation chamber data in conjunction with the above calculations based on Leeds gives the neutron plus proton particle flux profile at sea level and 40000 feet shown in Figure 8, while the ambient dose equivalent $\left(\mathrm{H}^{*}(10)\right)$ rates from all particles at 40000 feet are given in Figure 9. Peak rates are enhanced by about a factor 3 compared with the hourly average rates. Sea-level ambient dose equivalent rates at $2.5 \mathrm{GV}$ and $0 \mathrm{GV}$ are 0.6 and 2.5 microSieverts respectively and these levels are of little concern.

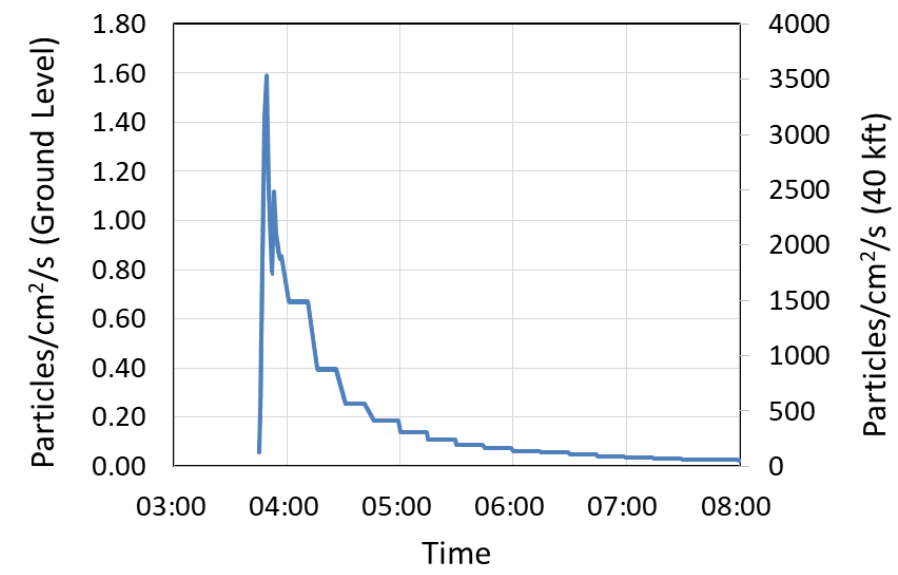

Figure 8. High temporal resolution ionisation chamber data from [18] are used in conjunction calculations based on the Leeds neutron monitor to give worst case particle (neutron plus proton) flux profiles at ground level and 40000 feet for the Feb56 event.

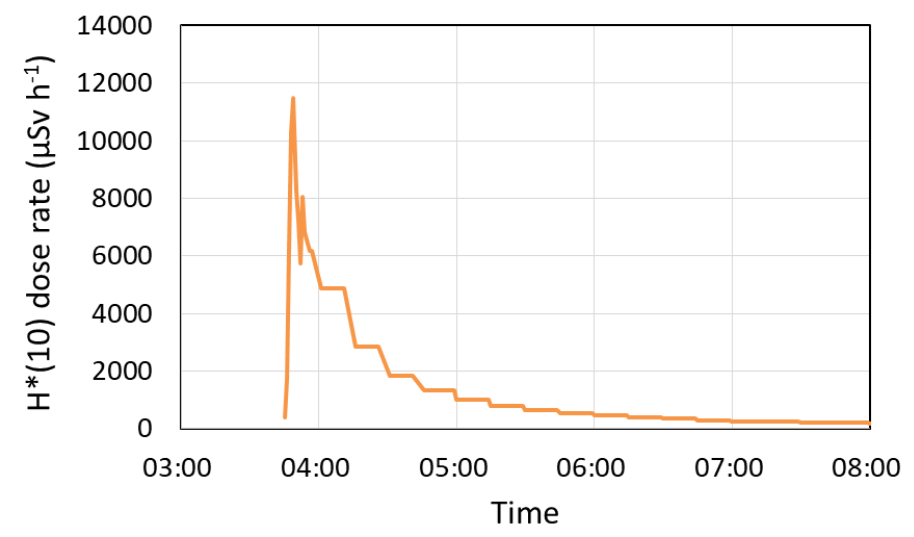

Figure 9. As for Figure 8 the worst case ambient dose equivalent rate is calculated for the Feb56 event at 40000 feet.

\section{FEB56 Scale}

At present there is no real-time system available for quantifying atmospheric radiation hazards and an urgent programme of flight monitors combined with ground 


\section{Paper presented at IEEE Nuclear and Space Radiation Effects Conference, New Orleans, 17-21 July 2017 Accepted for publication in IEEE Transactions on Nuclear Science, January 2018}

monitors and modelling is required. While such systems are being developed we suggest that a scale involving multiples of the Feb56 event could be used to give a quick and crude assessment of the atmospheric radiation hazard. The highest observed ground-level neutron monitor increase over 15 minutes can be compared with the value of $4581 \%$ for Feb56 to assess potential hazards using Table 4. Extrapolation to other altitudes can be made using Table 1 and the MAIRE software.

TABLE 4

FEB56 HAZARD SCALE

\begin{tabular}{|c|c|c|c|}
\hline $\begin{array}{c}\text { Peak flux } \\
\text { relative to } \\
\text { Feb56 }\end{array}$ & $\begin{array}{c}\text { Estimated } \\
\text { Recurrence } \\
\text { Time (years) } \\
\text { from Fig. 3 }\end{array}$ & $\begin{array}{c}\text { Worst case } \\
\text { route ambient } \\
\text { dose equivalent } \\
\text { mSv at 40000 } \\
\text { feet, } 0 \mathrm{GV}\end{array}$ & $\begin{array}{c}\text { Worst case } \\
\text { neutron plus } \\
\text { proton fluence } \\
\mathrm{cm}^{-2} \mathrm{hr}^{-1} \text { at } \\
40000 \text { feet, } 0 \\
\mathrm{GV}\end{array}$ \\
\hline 0.01 & 3 & 0.07 & $6.2 \times 10^{4}$ \\
\hline 0.1 & 12 & 0.7 & $6.2 \times 10^{5}$ \\
\hline 0.5 & $\begin{array}{c}24 \text { to } 36(14 \\
\text { from ref [16] }\end{array}$ & 3.5 & $3.1 \times 10^{6}$ \\
\hline 1.0 & 40 to 70 & 7.0 & $6.2 \times 10^{6}$ \\
\hline 4.0 & 140 to 190 & 28.0 & $2.5 \times 10^{7}$ \\
\hline 10.0 & 500 & 70.0 & $6.2 \times 10^{7}$ \\
\hline 30.0 & 1200 & 210 & $1.8 \times 10^{8}$ \\
\hline 50 & 10000 & 350 & $3.1 \times 10^{8}$ \\
\hline
\end{tabular}

For example for the event of 29 September 1989, the peak ground level neutron monitor increase was 395\% [15] and this would scale to give a worst case route (high latitude, 40000 feet) dose of $0.6 \mathrm{mSv}$, which is in reasonable agreement (factor 2) with more accurate estimation methods, e.g. [38-39]. For events at 0.01Feb56 the doses need adding to the medical records while at 0.1 Feb56 the doses start to exceed certain recommended limits (notably the $0.5 \mathrm{mSv}$ limit during pregnancy recommended by the Federal Aviation Authority). The level at which SEE rates become hazardous are system dependent and require system level analyses. However, as illustrated in Table 3, upset and failure rates at device level are significant at $1 \mathrm{xFeb} 56$ levels.

\section{DISCUSSION}

As can be seen above, the SEE rates and ambient dose equivalent rates at altitude can be very significant, even for the event of 23 February 56, which has a recurrence probability of 1 per 40 to 70 years. For a recurrence probability of 1 in 150 years the numbers increase 4-fold and for 1 per 1240 years 26-fold [22]. Safety-critical industries, including aviation, need to set design and avoidance levels taking account of these numbers. Protection against these events is a far greater challenge than for background cosmic ray rates due to the possibility of multiple upsets in several systems in a short space of time. For Feb56 the rates at 40000 feet are some 1000x higher than for background cosmic-ray rates at this altitude. In safety planning for aviation the influence of dose on crew and passengers must also be considered. For instance an event comparable to the Feb56 event could give the recommended annual dose limits used in Europe for aircrew $(6 \mathrm{mSv})$ in a single high latitude flight. Many flights now reach 43000 feet for which flux rates are increase some $30 \%$ with respect to 40000 feet and executive jets reach 49000 feet.

Gradients with respect to altitude are very steep, for example a factor 15 between 40000 feet and 20000 feet at $80^{\circ}$ North and so flying lower altitudes is highly beneficial if alerts can be provided in time. Indeed remaining on the ground would be the desired protection in extreme events. Agreement on hazard levels is required at international level, for example via the International Civil Aviation Authority (ICAO). There is also a strong latitude gradient (for example a factor 18 between $80^{\circ}$ North and $51^{\circ}$ North along the Greenwich meridian at 40000 feet) and this can be exploited to reduce the radiation hazard. However it should be noted that if an extreme geomagnetic storm is in progress this advantage is greatly diminished as the cut-off rigidities are lowered [39]. Indeed for the CarringtonHodgson event virtually no geomagnetic protection can be assumed as aurorae were seen in the tropics.

For ground-level systems the doses are not significant but SEE rates can be of concern, particularly for 1 in 150 or 1 in 1000 year events.

\section{CONCLUSION}

Severe atmospheric radiation environments are potentially hazardous and reasonably probable in comparison with other hazards (e. g. volcanic ash for air flights). Suggested worst-case environments and their probabilities given here should inform design and avoidance strategies. It is of high importance to maintain and utilise both ground-level and in-flight monitors together with reliable, real-time communications whilst acknowledging that these might not be available during an extreme ionospheric disturbance. It is recommended that a new space weather hazard scale relating to the Feb56 event be employed for warning and alert systems.

\section{ACKNOWLEDGMENT}

We acknowledge numerous valuable discussions with Ken McCracken, Peg Shea and Don Smart concerning neutron monitor data and cosmogenic nuclides. They also kindly provided the fine time resolution data from the ionisation chamber. Florian Mekhaldi is thanked for providing the results from the AD774 and AD993 events.

\section{REFERENCES}

[1] J.F. Ziegler editor, "Terrestrial cosmic rays and soft errors," dedicated volume of IBM Journal of Research and Development, Vol. 40, No. 1, Jan. 1996.

[2] E. Normand, "Single Event Upset at Ground Level", IEEE Trans. Nucl. Sci., Vol.43, Issue 6, pp. 2742-2750, Dec. 1996.

[3] C. S. Dyer, A. J. Sims, J. Farren, J. Stephen, "Measurements of the SEU Environment in the Upper Atmosphere," IEEE Tran. Nucl. Sci, NS-36, 6, pp. 2275-2280, Dec 1989.

[4] JESD89, "JEDEC standard on "Measurement and reporting of alphaparticle and terrestrial cosmic-ray induced soft errors in semiconductor devices," 2006.

[5] IEC-TS_62396-1 "Process management for avionics- Atmospheric radiation effects, Part-1: accommodation of atmospheric radiation effects via single event effects within avionics electronic equipment", BSi, 2006. (Issue 2 in 2011). 


\section{Paper presented at IEEE Nuclear and Space Radiation Effects Conference, New Orleans, 17-21 July 2017}

Accepted for publication in IEEE Transactions on Nuclear Science, January 2018

[6] C. S. Dyer, F. Lei, S. N. Clucas, D. F. Smart, M. A. Shea, "Solar particle enhancements of single event effect rates at aircraft altitudes", IEEE Trans. Nucl. Sci., Vol. 50, No. 6, pp. 2038-2045, Dec. 2003.

[7] IEC-TS 62396-6 "Process management for avionics- Atmospheric radiation effects Part 6: Extreme space weather and potential impact on the avionics environment and electronics," Technical Report, Jul. 2017.

[8] SAFESKY Institute [Online] Available:

https://vsp.ucar.edu/heliophysics/lws/safesky-lws-institute

[9] P. Cannon et al., "Extreme space weather: impacts on engineered systems and infrastructure," Royal Academy of Engineering, Feb. 2013.

[10] M.A. Shea, D.F. Smart, "Fifty years of cosmic radiation data," Space Science Reviews, 93, pp. 229-262, Jul. 2000.

[11] S. E. Forbush, "Three unusual cosmic-ray increases possibly due to charged particles from the Sun," Phys. Rev. 70, pp. 771-772, 1946.

[12] J. A. Simpson, "The Cosmic-Ray Nucleonic Component: The Invention and Scientific Uses of the Neutron Monitor," Space Science Reviews, 93, pp. 11-32, Jul. 2000.

[13] H. Rishbeth, M.A.Shea, D.F. Smart, "The solar-terrestrial event of 23 February 1956," Advances in Space Research, 44, pp. 1096-1106, 2009.

[14] S.P. Duggal, "Relativistic solar cosmic rays," Revs of Geophysics and Space Physics, Vol. 17, No. 5, pp. 1021-1057, Aug. 1979.

[15] K. McCracken, H. Moraal, M.A.Shea, "The high-energy impulsive ground-level enhancement," Ap. J. 761:101, Dec. 2012.

[16] Neutron Monitor Data-Base, [Online]. Available: http://swe.ssa.esa.int.

[17] University of Delaware Bartol Research Institute Neutron Monitor Program, [Online] Available http://neutronm.bartol.udel.edu/

[18] K. McCracken, M.A. Shea, D.F. Smart, "The short-lived $(<2$ minutes) acceleration of protons to $>13 \mathrm{GeV}$ in association with solar flares", presented at European Geosciences Union meeting, Vienna, Austria, Apr. 2016.

[19] K. McCracken, G. Dreschhoff, E. J. Zeller, D. Smart, and M. Shea (2001), "Solar cosmic ray events for the period 1561-1994: 1. Identification in polar ice 1561-1950," J. Geophys. Res., 106, pp. 21585 21598, Oct. 2001

[20] M.A. Shea, D.F. Smart, K. G. McCracken, G.A.M. Dreschhoff, H.E. spence, "Solar proton events for 450 years: The Carrington event in perspective," Advances in Space Research, 38, pp. 232-238, 2006.

[21] E. W. Wolff, M. Bigler, M. A. J. Curran, J. E. Dibb, M. M. Frey, M. Legrand, and J. R. McConnell, "The Carrington event not observed in most ice core nitrate records," Geophys. Res. Lett., 39, L08503, Apr. 2012. [22] F. Mekhaldi et al,"Multiradionuclide evidence for the solar origin of the cosmic-ray events of AD774/5 and 993/4." Nature Comms, 6:8611, Oct. 2015.

[23] K. G. McCracken and J. Beer," The annual cosmic-radiation intensities 1391-2014; The annual heliospheric magnetic field strengths 1391-1983, and identification of solar cosmic-ray events in the cosmogenic record 1800-1983," Solar Physics, 290, pp. 3051-3069, Nov. 2015.

[24] I. G. Usoskin and G. A. Kovoltsov, "Occurrence of extreme solar particle events: assessment from historical proxy data," Ap. J.,757:92, Sep. 2012.

[25] A. Tylka, W. Dietrich, "A new and comprehensive analysis of proton spectra in ground-level enhanced (GLE) solar particle events," Proceedings of the 31st International Cosmic Ray Conference (Lodz), 2009.

[26] "MAIRE," RadMod Research, [Online]. Available: www.radmod.co.uk/maire.

[27] A. Hands, F. Lei, K. Ryden, C. Dyer, C. Underwood, and C. Mertens, "New Data and Modelling for Single Event Effects in the Stratospheric Radiation Environment," IEEE Trans. on Nucl. Sci., Vol. 64, No. 1, pp. 587-595, Jan. 2017.

[28] J. M. Clem and L. I. Dorman, "Neutron Monitor Response Functions", Space Sci. Rev., vol. 93, pp. 335-359, Jul. 2000.

[29] A. Hands, C. Dyer and F. Lei, " SEU rates in aviation environments: variations due to cross-section fits and atmospheric models," IEEE Trans. on Nucl. Sci., Vol. 56, No. 4, pp. 2026-2034, Aug. 2009.

[30] S. I. Abe and Y. Watanabe, "Analysis of Charge Deposition and Collection Caused by Low Energy Neutrons in a 25-nm Bulk CMOS Technology," IEEE Trans. on Nucl. Sci., vol. 61, no. 6, pp. 3519-3526, Dec. 2014.

[31] Brian D. Sierawski et al.,"Muon-induced single event upsets in deepsubmicron technology," IEEE Trans. Nucl, Sci., 57, 6, 3273-3278, Dec. 2010.

[32] J. M. Trippe, R. A. Reed, R. A. Austin, B. D. Sierawski, R. A. Weller, E. D. Funkhouser, M. P. King, B. Narasimham, B. Bartz, R. Baumann, J. Labello, J. Nichols, R. D. Schrimpf and S. L.Weeden-Wright, "Electron- induced single event upsets in $28 \mathrm{~nm}$ and $45 \mathrm{~nm}$ bulk SRAMs", IEEE Trans. Nucl, Sci., vol.62, no.6, pp. 2709-2716, Dec 2015.

[33] K. Røed, M. Brugger, D. Kramer, P. Peronnard, C. Pignard, G. Spiezia, and A. Thornton., "Method for Measuring Mixed Field Radiation Levels Relevant for SEEs at the LHC," IEEE Trans. Nucl, Sci., vol. 59, no. 4, pp. 1040-1047, Aug. 2012.

[34] E. Normand, "Correlation of In-flight Neutron Dosimeter and SEU Measurements with Atmospheric Neutron Model," IEEE Trans. Nucl. Sci., 48, 6, 1996-2003, Dec. 2001

[35] C. Dyer, A. Hands, K. Ford, A. Frydland, P. Truscott, "Neutron-induced single event effects testing across a wide range of energies \& facilities and implications for standards, "IEEE Trans. Nucl, Sci., Vol. 53, No. 6, pp. 3596-3601, Dec. 2006.

[36] $R$. G. Alía et al., "SEL Cross Section Energy Dependence Impact on the High Energy Accelerator Failure Rate", IEEE Trans. Nucl, Sci., vol. 61, no. 6, pp. 2936-2944, Dec. 2014.

[37] A Hands, P. Morris, K. Ryden, C. Dyer, P. Truscott, A Chugg, S. Parker, "Single Event Effects in Power MOSFETs Due to Atmospheric and Thermal Neutrons" IEEE Trans. Nucl, Sci., Volume 58, No. 6, pp. 2687 - 2694, Dec. 2011.

[38] P. Lantos, N. Fuller, "History of the solar particle event radiation doses on-board aeroplanes using a semi-empirical model and Concorde measurements," Rad. Prot. Dos., Vol. 104, no. 3, pp. 199-210, 2003.

[39] C. Dyer, F. Lei, A. Hands, P. Truscott, "Solar particle events in the QinetiQ Atmospheric Radiation Model, " IEEE Trans. Nucl, Sci., Vol. 54, No. 4, pp. 1071-1075, Aug. 2007. 